An analysis of the mental health trajectories of university students compared to their community peers using a national longitudinal survey

Stefan Cvetkovski ${ }^{\mathrm{a}^{*}}$, Anthony F. Jorm ${ }^{\mathrm{a}}$, Andrew J. Mackinnon ${ }^{\mathrm{a}}$

a* Corresponding author: Stefan Cvetkovski, PhD candidate, Centre for Mental Health, Melbourne School of Population and Global Health, University of Melbourne, 207 Bouverie Street, Victoria 3010, Australia.

P: +61 3 90357793; F: +61 3 93495815. Email: scve@ student.unimelb.edu.au

a Anthony F. Jorm, Centre for Mental Health, Melbourne School of Population and Global Health, University of Melbourne, 207 Bouverie Street, Carlton, Victoria 3010, Australia. P: +61 3 90357799. Email: ajorm@unimelb.edu.au

${ }^{a}$ Andrew J. Mackinnon, Centre for Mental Health, Melbourne School of Population and Global Health, University of Melbourne, 207 Bouverie Street, Carlton, Victoria 3010, Australia. P: +61 403923 129. Email: andrew.mackinnon@ biostats.com.au

\title{
Acknowledgements:
}

This research was funded by an Australian National Health and Medical Research Council (NHMRC) postgraduate scholarship under Grant 1074750 to Cvetkovski and a NHMRC Fellowship under Grant 1059785 to Jorm.

This paper uses unit record data from the Household, Income and Labour Dynamics in Australia (HILDA) Survey. The HILDA Project was initiated and is funded by the Australian Government Department of Social Services (DSS) and is managed by the Melbourne Institute of Applied Economic and Social Research (Melbourne Institute). The findings and views reported in this paper, however, are those of the authors and should not be attributed to either DSS or the Melbourne Institute.

\section{Disclosure statement:}

The authors declare they have no conflict of interest.

\section{Ethical standards:}

This paper reports results based on the analysis of de-identified secondary data. Approval to access and analyse the HILDA data was obtained from the DSS. 


\begin{abstract}
This study examines the mental health trajectories of future/current undergraduate university students relative to their age-matched community peers from the ages of 15 to 21 . It analysed data from the Household, Income and Labour Dynamics in Australia survey. The sample comprised 442 students and 1,292 peers. Mental health was assessed with the 5-item Mental Health Inventory from the Short Form 36. The results showed that students generally had better mental health than their peers. This was largely associated with better parental mental health and socio-economic position. However, the models also revealed reductions in the mental health of students relative to their peers at ages prior to major transitions in their student careers. This study contributes to the literature on university student mental health by comparing the mental health trajectories of students with their community peers and by identifying the ages when student mental health programs may be of most benefit.
\end{abstract}

\title{
Keywords:
}

Mental health; university students; youth; socio-economic position; longitudinal structural equation modelling. 


\section{Introduction}

There is growing international concern about the reported poorer mental health of university students compared to their age-matched community peers (Ibrahim, Kelly, Adams, and Glazebrook, 2013; Larcombe et al., 2016; Leahy et al., 2010; Roberts, Golding, Towell, and Weinreb, 1999; Stallman, 2010; Stewart-Brown et al., 2000). Poor mental health can lead to a poorer educational experience generally, and may increase the likelihood of higher course non-completion rates, difficulties in completing coursework and lower grades (Hysenbegsi, Hass, and Rowland, 2005; Royal College of Psychiatrists, 2011; Stallman, 2010; Verger, Gilbert, and Kovess-Masfety, 2010). There are also potentially longer term and cumulative consequences of poor student mental health, such as lost career opportunities and, more generally, the development of a more prosperous and equitable society. Critically, most evidence regarding the poorer mental health of students comes from single institution, crosssectional studies, often with low response rates and possibly biased samples. There are few longitudinal studies available that can provide developmental insights into the mental health trajectories of students relative to their community peers (Andrews and Wilding, 2004; Cvetkovski, Reavley, and Jorm, 2012; Ibrahim et al., 2013; Zivin, Eisenberg, Gollust, and Golberstein, 2009).

Longitudinal studies that have examined the mental health of general populations of students have shown that student mental health is poorer during university study than before entry into a university course. For example, in a UK study, Andrews and Wilding (2004), found significant increases in both student anxiety and depression at mid-course compared to onemonth pre-entry into university. Similarly, the UK studies of Cooke et al. (2006) and Bewick et al. (2010), found that the mental health of students was significantly poorer in their firstyear of study compared to pre-entry into university. The study by Bewick et al. (2010) also 
followed students over their undergraduate course and found that their mental health was poorest in third-year and at no time returned to pre-entry levels.

A study by Hankin et al. (1998), which used longitudinal data from New Zealand, examined gender differences in the emergence of depression from pre-adolescence to young adulthood in university students and their peers. Five waves of data (at ages 11, 13, 15, 18 and 21) spanning 10 years were analysed. Their analyses showed significant effects for gender and age, and an age by gender interaction, but the rates of clinical depression and gender patterns of students were similar to their age-matched community peers.

While these longitudinal studies make useful contributions, they have some important limitations. With the exception of the study by Hankin et al. (1998), comparator data on peers were not collected, which makes it difficult to establish the specificity of the findings to university students. In addition, these studies did not time the repeated measures of mental health to allow investigation of key transition points into and over the course of university study. Furthermore, these studies did not examine the important effects of parent mental health and socio-economic position on the mental health of students and their community peers. Research has shown that a disadvantaged socio-economic position is associated with poorer mental health in adults (Fryers, Melzer, and Jenkins, 2003; Muntaner, Eaton, Miech, and O'Campo, 2004), and that both of these parent factors are associated with poorer mental health in their children (Amone-P'Olak, Burger, Muisman, Oldehinkel, and Ormel, 2011; Reiss, 2013). Given that young people are dependent on their parents for social, financial and material support, measures based on parent reports of their own mental health and socioeconomic position are important in establishing the socio-economic position of young people (Galobardes, Shaw, Lawlor, Lynch, and Smith, 2006). 
The current study sought to address the above limitations and to contribute to the longitudinal literature by using the Household Income and Labour Dynamics in Australia (HILDA) survey. The mental health trajectories of future/current students and their age-matched, nontertiary student peers were examined from the ages of 15 to 21 , with age 18 marking entry into university study for students. The study had two specific goals: first, to examine whether students had poorer mental health trajectories than their age-matched peers; and second, to examine whether there were any changes in the mental health trajectories of students relative to their age-matched community peers.

\section{Methods}

\section{Longitudinal dataset}

The study analysed 11 waves of data from the HILDA survey (Summerfield et al., 2012). This is an ongoing broad social and economic longitudinal survey conducted annually that began in 2001 with a large national probability sample of Australian households. The majority of interviews are conducted face-to-face and, in a small proportion of cases, by phone where necessary. Respondents also self-completed a questionnaire that contained more sensitive questions.

The wave 1 household response rate was $66 \%$, comprising 19,914 individuals. Of these household members, 4,787 were under the age of 15 , which left a sample of 15,127 people eligible for interview. Of these individuals, 13,969 completed the Person Questionnaire, representing a response rate of $92.3 \%$. The household response rates ranged from $87 \%$ in wave 2 to $71 \%$ in wave 11 . The attrition rates ranged from $13.2 \%$ in wave 2 to $3.5 \%$ in wave 11. The number of individuals who were interviewed in all 11 waves was 7,229 or $52 \%$ of the original sample. Further details about the survey can be found elsewhere (Summerfield et al., 2012). 


\section{Study design}

The models reported here used an accelerated longitudinal design (Duncan, Duncan, and Hops, 1996; Little, 2013; Willett, Singer, and Martin, 1998). This entailed re-organizing 11 waves of data (2001 to 2011) so that respondent age was the metric of time. This approach was used because the numbers of students starting undergraduate university degrees in any one wave of the HILDA survey (of any age) were small (e.g. from $n=113$ in 2003 to $n=124$ in 2008). Taking into account missing data and loss to follow-up, these sample sizes were insufficient to conduct meaningful longitudinal analyses using wave as the metric of time. The alternative of using year in undergraduate study for students as the metric of time was not possible as there is no equivalent metric of time for peers that could have provided a valid basis for longitudinal comparisons. The accelerated design using age as the metric of time has been shown to accurately replicate the results of a traditional longitudinal design (Duncan et al., 1996). Its strength over traditional designs is that it increases the sample size and, therefore, the power of the study. In addition, relevant age estimates are based on the contribution of all available birth cohorts over the period examined - i.e. the age specific estimates incorporate the average effect of birth cohort.

\section{Subsample}

The focus of the study is on undergraduate students who enrolled and started studying for bachelor degrees at age 18 . This age was chosen to mark the beginning of university study because it represents the typical student career trajectory. Approximately $43 \%$ of all students who started study from ages 17 to 21 started their study at age 18 .

All young people aged from 15 to 21 were initially selected for the study. They comprised 10 birth cohorts (1984-1993) from 11 waves of data. Young people who started university study before age 18 or from ages 19 to 21 , or for whom the start of study at age 18 could not be 
established, due to the timing of their entry into the HILDA survey or missing data, were excluded. Young people who studied for diploma level courses were excluded. Students with a one-year gap in their records, due to taking a year-off, were included. Young people who started university study after age 21 were included as peers over the ages examined. Finally, young people who enrolled in vocational education and training courses (i.e. certificate level I-IV) were included as peers over the ages examined.

This resulted in a sample of 442 students who started university study at age 18 (25\%) and 1,292 age-matched, non-tertiary student community peers (75\%). The vast majority of students studied full-time (91\% at age 18 and $73 \%$ by age 21$)$. Fifty percent of peers had studied or were studying for certificate level I-IV courses and the majority studied part-time (68\% at age 18 and $95 \%$ by age 21$)$.

\section{Measures}

The study outcome was a time-varying general mental health latent construct estimated at each age from 15 to 21 based on the repeated Mental Health Inventory (MHI-5) items from the Short Form 36 (SF-36). The MHI-5 has been shown to have good construct validity and reliability (Sanson-Fisher and Perkins, 1998; Ware and Gandek, 1998). The five repeated items refer to the past four weeks: 1) "Have you been a nervous person?" 2) "Have you felt so down in the dumps that nothing could cheer you up?" 3) "Have you felt calm and peaceful?” 4) “Have you felt down?” 5) "Have you been a happy person?” Responses are given on a six-point scale, ranging from "all of the time" to "none of the time". The items were rescaled so that the mental health construct ranged from 0-10. Higher scores indicate better mental health. (See dashed box in Figure 1 for an example of a MH construct at age 15.) 
The main predictor of interest was future/current university student status (students vs. peers). Other predictors of young person mental health included gender (female vs. male), a similarly structured, time-varying latent construct to that for young people for parent mental health based on parent responses to the MHI-5 items at each of their children's ages from 15 to 21. Responses from both parents on each MHI-5 item were combined to produce mean scores. Where there was a sole parent, their MHI-5 item scores were used alone. The items were rescaled so that the time-varying construct could range from $0-10$. Higher scores indicate better mental health. A construct for parent socio-economic position when their child was aged 15 was also estimated. This construct was measured with four combined indicators based on parent responses: lowest quartile of combined parent gross income from all sources; whether at least one parent was unemployed or not in the labour force; whether at least one parent reported financial difficulties (based on a positive response to at least one of 7 binary items: "Asked for help from welfare/community organisations"; "Went without meals"; "Was unable to heat home"; "Pawned or sold something"; "Could not pay the mortgage or rent on time"; "Asked for financial help from friends or family"; and "Could not pay electricity, gas or telephone bills on time"); and a continuous measure for parent occupational status that ranges from 0-100 (McMillan, Beavis, and Jones, 2009). Given that the latter measure does not include unemployed respondents, missing scores were imputed using “potential occupational status" based on the parents' highest educational attainment (McMillan et al., 2009). Parent occupational status was reverse coded and rescaled to range from 0-10. Higher scores indicate lower parent occupational status.

Some predictors were primarily treated as covariates and chosen for their potentially important confounding effects in the examination of the mental health trajectories of students relative to their community peers. These included whether the respondent was living with parents (yes vs. no). Whether the respondent was employed full-time or part-time (yes vs. 
no). We also used the well-established SF-36 physical functioning scale (Ware and Gandek, 1998) to adjust for young person physical health at each age. This scale is derived from 10 items and relates to activities during a typical day. Respondents were asked if their health limits any of these activities: 1) "Vigorous activities, such as running, lifting heavy objects, participating in strenuous sports"; 2) "Moderate activities, such as moving a table, pushing a vacuum cleaner, bowling or playing golf"; 3) "Lifting or carrying groceries"; 4) “Climbing several flights of stairs"; 5) "Climbing one flight of stairs"; 6) "Bending, kneeling, or stooping"; 7) "Walking more than one kilometre"; 8) "Walking half a kilometre"; 9) "Walking 100 metres"; and 10) "Bathing or dressing yourself". Responses are given on a three-point scale: 1) "Yes, limited a lot"; 2) "Yes, limited a little"; 3 ) "No, not limited at all". This summary scale was rescaled to range from 0-10. Higher scores indicate better physical health. Finally, 11 dummy variables were created for response period, from 2001 to 2011 (yes vs. no).

All continuous measures were rescaled to range from 0-10 for two reasons. First, the SF-36 MHI-5 and physical functioning measures are usually analysed as summary scales that range from 0-100 (see, e.g. Roberts et al., 1999; Stewart-Brown et al., 2000). These measures were rescaled to range from 0-10 to enable comparisons of university student and community peer mental health and physical functioning scores with previous studies - the scores reported below can be multiplied by 10. Second, longitudinal structural equation models (see below) can have convergence problems when the metrics of variables and/or latent constructs are widely different, such as when models contain both binary variables and scales or latent constructs that range from 0-100 (Little, 2013).

\section{Data analysis}


Descriptive statistics (percentages, means and standard deviations) are reported for the characteristics of students and their peers, along with any significant differences between the groups using chi-square tests, Wald tests and t-tests.

The substantive data analysis was conducted in the longitudinal structural equation modelling (SEM) framework and examined mean and covariance structures. An important strength of longitudinal SEMs is that levels of measurement invariance can be tested to establish that the constructs do not change over time as a result of measurement structure and error but represent true change (Geiser, 2013; Little, 2013). Latent state (LS) models were used to establish the mental health trajectories of young people empirically rather than hypothesising a particular form of change (e.g. linear, quadratic, etc.), as transient and nonlinear effects were anticipated. The LS models examined differences in mental health between future/current students and their age-matched peers from the ages 15 to 21 . LS models can also be reparameterized to produce models of latent change (LC) in mental health between adjacent ages (Geiser, 2013). LC models examined changes in mental health between adjacent ages in students relative to their age-matched peers. (See Figure 1 for a simplified path diagrams of the LS model with the predictors of interest. See also Figure S1 online for more detailed path diagrams of both the LS and LC models.)

Insert Figure 1 around here.

Missing data by design, non-response and dropout were treated as missing at random in substantive models using Mplus's MLR estimator (a full information maximum likelihood estimator with robust standard errors) (Little, 2013; Muthén and Muthén, 1998-2014). Model fit statistics reported include Chi-Square $\left(\chi^{2}\right)$, Root Mean Square Error of Approximation (RMSEA), comparative fit index (CFI) and Tucker-Lewis index (TLI). A value of $\leq 0.05$ on the RMSEA and $\geq 0.90$ on the CFI/TLI represent an acceptable model fit (Little, 2013). 
The mental health and socio-economic position constructs were first estimated separately to assess their fit to the data. For repeated measures constructs, tests of measurement invariance were conducted and the highest level of measurement invariance achieved was used in substantive models. At least strong factorial invariance (i.e. invariant factor loadings and intercepts) is required to ensure that the same construct is measured over time and accounts for measurement error (Geiser, 2013; Little, 2013). Confirmatory factor analysis (CFA) based scale reliabilities $(\rho)$ (Raykov, 2004) are also reported for all constructs. Given the sensitivity of the Chi-Square statistic to sample size, measurement invariance was assessed with the CFI. A cut-off 0.01 for change in CFI value was used to evaluate added invariance constraints (Little, 2013). Cronbach's Alphas ( $\alpha$ ) are also reported for the physical functioning scale.

Initial LS and LC models examined the effect of future/current student status on the mental health trajectories of young people. Subsequent models examined the effect of student status adjusting for gender, and then the other predictors, adjusting for gender. Finally, models examining the simultaneous effects of student status and the other predictors on young person mental health were estimated. All models were adjusted for the effect of response period.

Unstandardized regression coefficients with 95\% confidence intervals (CIs) are reported, together with the p-value cut-offs $<0.05,<0.01$, and $<0.001$. Cohen's effect sizes $(d)$ are also reported. All data analyses were conducted with Stata IC/13.1 (StataCorp, 2013) and Mplus V 7.3 (Muthén and Muthén, 1998-2014).

\section{Results}

\section{Characteristics of university students and their community peers}

Table 1 shows that future/current students had slightly longer age-specific mental health records, and significantly better mental health than their peers at ages 15, 16, 18, 19 and 21 . 
Students comprised larger proportions of females and young people living with their parents than peers. Students had better physical functioning than peers at all ages. The parents of students consistently had better mental health than the parents of peers. Compared to parents of peers, they also had smaller proportions with combined incomes from all sources in the lowest quartile, who were unemployed or not in the labour force, and with financial difficulties. Parents of students had significantly higher occupational status than parents of peers.

Insert Table 1 around here.

The proportion of students employed (full-time or part-time) was similar to peers over the ages examined with the exception of age 17 , when there was a significantly smaller proportion of students who were employed ( $48 \%$ vs. $\left.56 \%, \chi_{(1)}^{2}=7.02, p<0.01\right)$ (see online Table S1).

\section{Construct measurement invariance and scale reliability}

Repeated young person and parent mental health constructs achieved better than strong factorial invariance - i.e. invariant construct variance in addition to loadings and intercepts. All construct models fitted the data well and scale reliabilities were acceptable: age-specific young person mental health $\rho \geq 0.837$; young person age-specific parent mental health $\rho \geq$ 0.896; and parent socio-economic position when their child was aged $15 \rho=0.713$. The timevarying physical functioning scale also had good scale reliabilities: age-specific $\alpha \geq 0.948$. (See online, Tables S2-S5 and the section on parent socio-economic position, for details of measurement invariance tests, and final model factor loadings and CFA-based scale reliabilities. See also Tables S5-S12 for the physical functioning scale reliabilities.)

\section{The effect of university study on mean mental health trajectories}


Model 1 in Table 2 shows the effect of future/current student status on the mental health trajectories of young people from ages 15 to 21 . The model fitted the data well. Young people who went on to university study at age 18 had better mental health than their peers at ages 15 , 16, 18, 19 and 21 (see also Figure 2, Panel A).

Model 2, which adjusted for gender, also fitted the data well and showed similar results to Model 1. However, the addition of gender increased the student status effect sizes.

Model 3 added an adjustment for the time-varying effects of parent mental health and also showed a good fit to the data. The mental health of students remained significantly better than their peers at ages $15,16,18$ and 19.

Model 4 adjusted for the effect of parent socio-economic position when their child was aged 15 and showed that the mental health of students remained significantly better than their peers at ages 15, 16, 18, 19, and 21. (Due to the use of numerical integration, overall model fit statistics are not available for Model 4.)

In Model 5, which adjusted for all other predictors, the effect of student status on mental health was attenuated. Students had better mental health than their peers only at ages 15 and 18. (Due to the use of numerical integration, overall model fit statistics are not available for Model 5. See Figure 2, Panel B, for the fully adjusted trajectories and online Table S6 for full results.)

Insert Table 2 around here.

Insert Figure 2(a) and Figure 2(b) horizontally around here. 
Young people who went on to university study had a significant reduction in mental health from age 16 to $17(\mathrm{~b}=-0.31$ (95\%CI: $-0.53,-0.09), p<0.01 ; d=-0.18)$, then a significant increase from age 17 to 18 ( $\mathrm{b}=0.41$ (95\%CI: $0.19,0.63), p<0.001 ; d=0.24)$, then a significant reduction again from age 19 to 20 ( $b=-0.35$ (95\%CI: $-0.62,-0.08), p<0.05 ; d=-$ 0.20), and then a significant increase again from age 20 to 21 ( $b=0.32$ (95\%CI: 0.03, 0.60), $p<0.05 ; d=0.18$ ) relative to their peers (see Figure 2, panel A, and Model 1 in online Table S6). This pattern of significant change in mental health between adjacent ages was generally robust in models with the other predictors (see Figure 2, panel B, for the fully adjusted trajectories and online Table S7, Models 2-8).

\section{The effects of the other predictors on mean mental health trajectories}

Gender

All models showed that females had significantly poorer mental health than males at all ages. These differences peaked at age 17 and then reduced from ages 18 to 21 (see Table 2, Model 2).

\section{Parent mental health}

Better parent mental health was significantly associated with better mental health in their children at all ages. With adjustment for all other predictors, most effect sizes were attenuated and significant only for ages 15, 17, 19, 20 and 21. (See Table 2, Models 3 and 5).

\section{Parent socio-economic position when their child was aged 15}

A disadvantaged parent socio-economic position when their child was aged 15 was significantly associated with poorer mental health in their children at ages 15, 16, 17, 18 and 20 (see Table 2, Models 4). With adjustment for all other predictors, effect sizes on young 
person mental health of \pm 1 SD difference in parent socio-economic position (i.e. relative disadvantage vs. advantage) increased (see Table 2, Models 5). It should be noted that parent socio-economic position was moderately and negatively correlated with parent mental health at all ages - i.e. the more disadvantaged the socio-economic position of parents, the poorer their own mental health trajectories $(15 r=-0.47, p<0.001 ; 16 r=-0.49, p<0.001 ; 17 r=-0.47$, $p<0.001 ; 18 r=-0.45, p<0.001 ; 19 r=-0.44, p<0.001 ; 20 r=-0.45, p<0.001,21 r=-0.42$, $p<0.001)$.

The effect of the other predictors on changes in mean mental health between adjacent ages

Parent mental health was positively associated with an improvement in young person mental health from the age of 16 to 17 ( $\mathrm{b}=0.08$ (95\%CI: $0.01,0.15), p<0.05, \pm 1 \mathrm{SD} d=0.16)$ and 18 to 19 ( $\mathrm{b}=0.11(95 \% \mathrm{CI}: 0.04,0.19), p<0.01, \pm 1 \mathrm{SD} d=0.22)$. After adjustment for all other predictors, parent mental health remained positively associated with an improvement in young person mental health only from age 18 to 19 , with an increased effect size $(b=0.16$ (95\%CI: 0.06, 0.25), $p<0.01 ; \pm 1 \mathrm{SD} d=0.31$ ), and from age 20 to 21 (b=0.13 (95\%CI: 0.01, 0.26), $p<0.05 ; \pm 1$ SD $d=0.26$ ). (For full results, see online Table S7, Models 6 and 8).

\section{Discussion}

Using the HILDA survey, we showed that, while the effect sizes were small, future/current university students had statistically significant better mental health than their peers at ages 15 , 16, and during university study, at ages 18, 19 and 21. Even with adjustment for all other predictors, students had better mental health than peers at age 15 and the first-year of their undergraduate study at age 18 . There were two statistically significant negative deviations in the mental health trajectories of students, from ages 16 to 17 and 19 to 20 , and two positive deviations, from ages 17 to 18 and 20 to 21 , relative to their age-matched peers. 
These results contrast with previous cross-sectional studies, which found that students had poorer mental health than their age-matched peers (see, e.g., Ibrahim et al., 2013; Larcombe et al., 2016; Leahy et al., 2010; Roberts et al., 1999; Stallman, 2010; Stewart-Brown et al., 2000). A large part of this discrepancy is likely to be due to methodological limitations of previous work, including the use of single university or college samples, low response rates and possible response biases (Cvetkovski et al., 2012).

The results of the current study also challenge the few longitudinal studies available. Reasons for these discrepancies may include: not accounting for measurement error in repeated mental health measures (see, e.g., Andrews and Wilding, 2004; Bewick et al., 2010; Cooke et al., 2006; Hankin et al., 1998), which is one of the most important considerations in longitudinal research, since without establishing measurement invariance, it is difficult to interpret any changes in mental health over time (Geiser, 2013; Little, 2013); not collecting meaningful pre-university study measures, e.g. only one baseline measure when young people had already been offered a place at a university, which provides no insight into the mental health of young people prior to being offered a place at a university (see, e.g., Andrews and Wilding, 2004; Bewick et al., 2010; Cooke et al., 2006, where the pre-university baseline questionnaire was sent with the registration pack to students); important gaps in data collection at ages where significant interruptions in the mental health of students were observed in the current study (e.g. ages 17 and 20), and the use of a single birth cohort, which may not have been representative of other birth cohorts due to period effects (e.g. Hankin et al., 1998). Finally, it is also important to note that the effects of university study on mental health may differ between countries. However, the current study is concordant with the UK findings of Bewick et al. (Bewick et al., 2010) (a realm with a tertiary education environment arguably more similar to Australia's than that of many other countries). These researchers 
collected data over three consecutive years and found that student mental health was poorest in the third-year of undergraduate studies.

The current study found that adjusting for both parent mental health and socio-economic position when their child was aged 15 could largely account for the better mental health of students relative to their age-matched peers, with the exception of age 15 and the first year of university study at age 18 . These findings are consistent with previous research on young people (Amone-P'Olak et al., 2011): a one standard deviation above vs. below mean levels on these parent constructs was associated with independent and moderate-sized effects on the mental health of their children at the key ages of 17, 18 and 20 - i.e. the more disadvantaged the socio-economic position of parents and the poorer their mental health, the poorer the mental health of their children. These findings are also consistent with previous research on adults (Fryers et al., 2003; Kaplan, Shema, and Leite, 2008; Muntaner et al., 2004): parent mental health and socio-economic position were moderately and negatively correlated - i.e. the more disadvantaged the socio-economic position of parents, the poorer their own mental health trajectories. Without adjustment for parent mental health and socio-economic position constructs in studies that compare the mental health of students with age-matched peers, any observed differences are likely to be biased. The models showed that without parent socioeconomic position when their child was aged 15, the effect of parent mental health was overestimated, while without parent mental health, the effect of parent socio-economic position when their child was aged 15 was underestimated. Despite the growth in higher education in Australia over the last 25 years, students still largely come from a relatively advantaged socio-economic position (Department of Education Employment and Workplace Relations, 2008). Further research is needed to examine in more detail how lack of social, financial and material resources, and the associated limited action possibilities, lead to the 
emergence of poor mental health in young people (Holzkamp-Osterkamp, 1991; Holzkamp, 1992).

Importantly, while the effect sizes for the changes in the mental health of students relative to their peers were small, these were not explained by the potential confounders. These interruptions in characteristic mental health seem to involve factors specific to the developmental aspects of student careers. In particular, there was a reduction in the mental health of future/current students from age 16 to 17, which marks a typically stressful period in the final-year of secondary school at age 17, when students were working towards achieving the grades required for entry into university studies, without knowing whether they would be successful; and then again in the third-year of their undergraduate studies at age 20, when they were again working towards completing their course and were deciding whether they would enter the work force or, if their grades and circumstances allowed, go on to further study in an honours or fourth-year. The two improvements in mental health occurred from age 17 to 18 , which marked entry into first-year university study, and then again from age 20 to 21, which marked entry into further study in an honours or fourth-year. Further research is required to examine the effect on mental health of study loads in the context of student perceptions of potential career trajectories and evolving labour market conditions for graduates (Tomlinson, 2008).

The findings of this study have implications for policies, programs and interventions aimed at addressing the mental health of young people in general and students in particular. Generally, the results show that a disadvantaged socio-economic position has negative consequences for the mental health of young people. Social and economic policies aimed at reducing socioeconomic inequalities and generating structures of opportunity for adults are likely to have a positive effect on the mental health of parents and, in turn, the mental health of their children 
(Reiss, 2013). In the longer term it may increase the university participation rate of currently disadvantaged groups of young people. Specifically, in relation to students, it appears that the most appropriate time for mental health programs or interventions in secondary school is in the final and most stressful year at age 17. It is at this age that students may benefit most from guidance on careers, managing general and study-related stresses, before the transition into university study. Once at university, the most stressful year for students is third-year at age 20. It is at this age that students may benefit the most from mental health programs or interventions that help them manage their general, study and career planning-related stresses, before the transition into the work force or further study (Bewick et al., 2010).

\section{Limitations}

The current study has some limitations that need to be considered. First, the study analysed general mental health trajectories and each age-specific measure related to the last fourweeks. Specific mental disorders may have different trajectories. Another limitation is that students who started study at ages 17, 19, 20 and 21 were not included, and their mental health trajectories may have differed to those who started study at age 18. However, it is worth reiterating that, of the students who started study from the ages of 17 to $21,43 \%$ started their first-year of study at age 18. Finally, it should also be noted that there is evidence that young people who were most likely to drop-out of the HILDA survey were from a disadvantaged socio-economic position (Summerfield et al., 2012). Consequently, the estimates of better student mental health are likely to be conservative.

\section{Conclusions}

This study found that secondary students who went on to become university students generally had better mental health than their age-matched peers. The better mental health and socio-economic position of their parents largely explained students' better mental health, with 
the exception of age 15 and the first-year of university study at age 18 . However, there were significant reductions in the mental health of students relative to their age-matched peers at ages prior to major transitions in their educational careers, at age 17 in the final-year of secondary school, and at age 20 in the third-year of their university studies. These findings suggest that additional and better policies aimed at reducing socio-economic inequalities in adults may improve the mental health of parents and their children, and in the longer term, increase the university participation rate of currently disadvantaged young people. Furthermore, mental health programs or interventions aimed at assisting students with their general, study and career planning-related stresses may be of most benefit during the most stressful ages prior to major transitions in their student careers. 


\section{References}

Amone-P'Olak, K, H. Burger, M. Muisman, A. J. Oldehinkel, and J. Ormel. 2011. "Parental Psychopathology and Socioeconomic Position Predict Adolescent Offspring's Mental Health Independently and Do Not Interact: The TAILS Study.” Journal of Epidemiology and Community Health, 65 (1): 57-63.

Andrews, B., and J. M. Wilding. 2004. "The Relation of Depression and Anxiety to LifeStress and Achievement in Students.” British Journal of Psychology, 95: 509-521.

Bewick, B., G. Koutsopoulou, J. Miles, S. Slaa, and M. Barkham. 2010. "Changes in Undergraduate Students' Psychological Well-Being as They Progress through University." Studies in Higher Education, 35 (6): 633-645.

Cooke, R., B. M. Bewick, M. Barkham, M. Bradley, and K. Audin. 2006. "Measuring, Monitoring and Managing the Psychological Well-Being of first Year University Students.” British Journal of Guidance \& Counselling, 34 (4): 505-517.

Cvetkovski, S., N. J. Reavley, and A. F. Jorm. 2012. "The Prevalence and Correlates of Psychological Distress in Australian Tertiary Students Compared to Their Community Peers." Australian and New Zealand Journal of Psychiatry, 46: 457-467.

Department of Education Employment and Workplace Relations. 2008. Review of Australian Higher Education. Canberra: Australian Government.

Duncan, S. C., T. E. Duncan, and H. Hops. 1996. "Analysis of Longitudinal Data within Accelerated Longitudinal Designs.” Psychological Methods, 1 (3): 236-248.

Fryers, T., D. Melzer, and R. Jenkins. 2003. "Social Inequalities and the Common Mental Disorders: A Systematic Review of the Evidence." Social Psychiatry and Psychiatric Epidemiology, 38: 229-237.

Galobardes, B., M. Shaw, D. A. Lawlor, J. W. Lynch, and G. D. Smith. 2006. "Indicators of Socioeconomic Position (Part 1)." Journal of Epidemiology and Community Health, 60: 7-12.

Geiser, C. 2013. Data Analysis with Mplus. New York: Guilford Press.

Hankin, B. L., L. Y. Abramson, T. E. Moffitt, P. A. Silva, and R. McGee. 1998. "Development of Depression from Preadolescence to Young Adulthood: Emerging Gender Differences in a 10-Year Longitudinal Study." Journal of Abnormal Psychology, 107: 128-140.

Holzkamp-Osterkamp, U. 1991. "Emotion, Cognition, and Action Potence." In Critical Psycology: Contributions to an Historical Science of the Subject, edited by C. W. Tolman \& W. Maiers, 102-133. New York: Cambridge University Press.

Holzkamp, K. 1992. “On Doing Psychology Critically.” Theory \& Psychology, 2 (2): 193 204. 
Hysenbegsi, A., S. L. Hass, and C. R. Rowland. 2005. "The Impact of Depression on the Academic Productivity of University Students." The Journal of Mental Health Policy and Economics, 8: 145-151.

Ibrahim, A. K., S. J. Kelly, C. E. Adams, and C. Glazebrook. 2013. "A Systematic Review of Studies of Depression Prevalence in University Students." Journal of Psychiatric Research, 47: 391-400.

Kaplan, G. A., S. J. Shema, and C. M. A. Leite. 2008. "Socioeconomic Determinants of Psychological Well-Being: The Role of Income, Income Change, and Income Sources During the Course of 29 Years." Annals of Epidemiology, 18: 531-537.

Larcombe, W., S. Finch, R. Sore, C. M. Murray, S. Kentish, R. A. Mulder, P. Lee-Stecum, C. Baik, O. Tokatlidis, and D. A. Williams. 2016. "Prevalence and Socio-Demographic Correlates of Psychological Distress among Students at an Australian University." Studies in Higher Education, 41 (6): 1074-1091.

Leahy, C. M., R. F. Peterson, I. G. Wilson, J. W. Newbury, A. L. Tonkin, and D. Turnbull. 2010. "Distress Levels and Self-Reported Treatment Rates for Medicine, Law, Psychology and Mechanical Engineering Students: Cross-Sectional Study." Australian and New Zealand Journal of Psychiatry, 44: 608-615.

Little, Todd D. 2013. Longitudinal Structural Equation Modeling. New York: Guilford Press.

McMillan, J., A. Beavis, and F. L. Jones. 2009. "The AUSEI06: A New Socioeconomic Index for Australia.” Journal of Sociology, 45 (2): 123-149.

Muntaner, C., W. W. Eaton, R. Miech, and P. O'Campo. 2004. "Socioeconomic Position and Major Mental Disorders.” Epidemiologic Reviews, 26: 53-62.

Muthén, L. K., and B. O. Muthén. 1998-2014. Mplus User's Guide. Seventh ed. Los Angeles, CA: Muthén \& Muthén.

Raykov, T. 2004. "Behavioral Scale Reliability and Measurement Invariance: Evaluation Using Latent Variable Modeling.” Behavior Therapy, 35: 299-331.

Reiss, F. 2013. "Socioeconomic Inequalities and Mental Health Problems in Children and Adolescents: A Systematic Review.” Social Science and Medicine, 90: 24-31.

Roberts, R., J. Golding, T. Towell, and I. Weinreb. 1999. "The Effects of Economic Circumstances on British Students' Mental and Physical Health.” Journal of American College Health, 48: 103-109.

Royal College of Psychiatrists. 2011. The Mental Health of Students in Higher Education. London: Royal College of Psychiatrists.

Sanson-Fisher, R. W., and J. J. Perkins. 1998. "Adaptation and Validation of the SF-36 Health Survey for Use in Australia." Journal of Clinical Epidemiology, 51 (11): 961967.

Stallman, H. M. 2010. "Psychological Distress in University Students: A Comparison with General Population Data." Australian Psychologist, 45 (4): 249-257. 
StataCorp. 2013. Stata: Release 13. Statistical Software. College Station, TX: StataCorp LP.

Stewart-Brown, S., J. Evans, J. Patterson, S. Peterson, H. Doll, J. Balding, and D. Regis. 2000. "The Health of Students in Institutes of Higher Education: An Important and Neglected Public Health Problem?” Journal of Public Health Medicine, 22 (4): 492499.

Summerfield, M., S. Freidin, M. Hahn, P. Ittak, N. Li, N. Macalalad, R. Wilkins, and M. Wooden. 2012. Hilda User Manual - Release 11. Melbourne: Melbourne Institute of Applied Economic and Social Research, University of Melbourne. Accessed February 42017.

https://www.melbourneinstitute.com/downloads/hilda/User\%20Manual/HILDA\%20U ser\%20Manual\%20Release_11.0.pdf.

Tomlinson, M. 2008. “"The Degree Is Not Enough': Students' Perceptions of the Role of Higher Education Credentials for Graduate Work and Employability." British Journal of Sociology of Education, 29 (1): 49-61.

Verger, P., F. Gilbert, and V. Kovess-Masfety. 2010. "Psychiatric Disorders in Students in Six French Universities: 12-Month Prevalence, Comorbidity, Impairment and HelpSeeking." Social Psychiatry and Psychiatric Epidemiology, 45: 189-199.

Ware, J. E., and B. Gandek. 1998. "Overview of the Sf-36 Health Survey and the International Quality of Life Assessment (IQOLA) Project.” Journal of Clinical Epidemiology, 51 (11): 903-912.

Willett, J. B., J. D. Singer, and N. C. Martin. 1998. "The Design and Analysis of Longitudinal Studies of Development and Psychopathology in Context: Statistical Models and Methodological Recommendations." Development and Psychopathology, 10: 395-426.

Zivin, K., D. Eisenberg, S. E. Gollust, and E. Golberstein. 2009. "Persistence of Mental Health Problems and Needs in a College Student Population." Journal of Affective Disorders, 117: 180-185. 


\section{Tables}

Table 1. Characteristics of university students and community peers: ages 15 to 21 (student $n=442$; peer $n=1292$ ).

\begin{tabular}{|c|c|c|c|c|c|}
\hline Characteristic & $\begin{array}{l}\text { Sub- } \\
\text { group }\end{array}$ & $\begin{array}{l}\text { University } \\
\text { students }\end{array}$ & $\begin{array}{l}\text { Community } \\
\text { peers }\end{array}$ & Total & $\begin{array}{l}\chi^{2} \text { ort-test } \\
p \text {-values }\end{array}$ \\
\hline $\begin{array}{l}\text { Young person mental health record } \\
\text { length: M (SD) }\end{array}$ & & $5.03(1.53)$ & $4.50(1.72)$ & $4.63(1.69)$ & $<0.001$ \\
\hline \multirow{7}{*}{$\begin{array}{l}\text { Young person mental health } \\
\text { construct scores: } \mathrm{M}(\mathrm{SD})^{\mathrm{a}}\end{array}$} & 15 & $7.74(1.22)$ & $7.46(1.53)$ & $7.53(1.46)$ & $<0.001$ \\
\hline & 16 & $7.62(1.50)$ & $7.35(1.82)$ & $7.42(1.75)$ & $<0.01$ \\
\hline & 17 & $7.44(1.62)$ & $7.36(1.79)$ & $7.38(1.75)$ & NS. \\
\hline & 18 & $7.69(1.52)$ & $7.36(1.72)$ & $7.45(1.68)$ & $<0.001$ \\
\hline & 19 & $7.68(1.28)$ & $7.40(1.58)$ & $7.47(1.51)$ & $<0.001$ \\
\hline & 20 & $7.52(1.35)$ & $7.38(1.57)$ & $7.42(1.52)$ & NS. \\
\hline & 21 & $7.69(1.14)$ & $7.47(1.37)$ & $7.52(1.32)$ & $<0.01$ \\
\hline \multirow[t]{2}{*}{ Gender: n (Col \%) } & Males & $192(43.4)$ & $730(56.5)$ & $922(53.2)$ & \\
\hline & Females & $250(56.6)$ & $562(43.5)$ & $812(46.8)$ & $<0.001$ \\
\hline \multirow[t]{7}{*}{ Physical functioning: $\mathrm{M}(\mathrm{SD})^{\mathrm{b}}$} & 15 & $9.31(1.79)$ & $8.88(2.27)$ & $9.00(2.16)$ & $<0.01$ \\
\hline & 16 & $9.50(1.42)$ & $8.82(2.39)$ & $9.01(2.19)$ & $<0.001$ \\
\hline & 17 & $9.53(1.35)$ & $8.95(2.20)$ & $9.10(2.03)$ & $<0.001$ \\
\hline & 18 & $9.55(1.40)$ & $8.97(2.13)$ & $9.14(1.97)$ & $<0.001$ \\
\hline & 19 & $9.71(0.92)$ & $9.10(2.02)$ & $9.29(1.78)$ & $<0.001$ \\
\hline & 20 & $9.66(1.03)$ & $9.16(1.91)$ & $9.31(1.70)$ & $<0.001$ \\
\hline & 21 & $9.57(1.20)$ & $9.19(1.91)$ & $9.31(1.73)$ & $<0.01$ \\
\hline \multirow[t]{14}{*}{ Living with parents: n (Col \%) } & 15 Yes & --- & --- & --- & \\
\hline & No & --- & --- & --- & \\
\hline & 16 Yes & --- & --- & --- & \\
\hline & No & --- & --- & --- & \\
\hline & 17 Yes & $382(96.7)$ & $929(86.9)$ & $1311(89.6)$ & \\
\hline & No & $13(3.3)$ & $140(13.1)$ & $153(10.4)$ & $<0.001$ \\
\hline & 18 Yes & $339(83.7)$ & $783(75.4)$ & $1122(77.8)$ & \\
\hline & No & $66(16.3)$ & $255(24.6)$ & $321(22.2)$ & $<0.01$ \\
\hline & 19 Yes & $243(78.4)$ & $497(65.5)$ & $740(69.2)$ & \\
\hline & No & $67(21.6)$ & $262(34.5)$ & $329(30.8)$ & $<0.001$ \\
\hline & 20 Yes & $180(72.6)$ & $362(57.1)$ & $542(61.5)$ & \\
\hline & No & $68(27.4)$ & $272(42.9)$ & $340(38.5)$ & $<0.001$ \\
\hline & 21 Yes & $128(68.5)$ & $233(47.2)$ & $361(53.0)$ & \\
\hline & No & $59(31.5)$ & $261(52.8)$ & $320(47.0)$ & $<0.001$ \\
\hline \multirow{7}{*}{$\begin{array}{l}\text { Parent mental health construct } \\
\text { scores: } \mathrm{M}(\mathrm{SD})^{\mathrm{a}}\end{array}$} & 15 & $7.68(1.19)$ & $7.34(1.46)$ & $7.43(1.40)$ & $<0.001$ \\
\hline & 16 & $7.81(1.21)$ & $7.31(1.56)$ & $7.44(1.49)$ & $<0.001$ \\
\hline & 17 & $7.86(1.17)$ & $7.36(1.55)$ & $7.49(1.48)$ & $<0.001$ \\
\hline & 18 & $7.98(1.20)$ & $7.42(1.65)$ & 7.57 (1.57) & $<0.001$ \\
\hline & 19 & $7.90(1.17)$ & $7.42(1.47)$ & $7.54(1.41)$ & $<0.001$ \\
\hline & 20 & $7.93(1.13)$ & $7.49(1.40)$ & $7.60(1.35)$ & $<0.001$ \\
\hline & 21 & $8.06(1.08)$ & $7.50(1.48)$ & $7.64(1.41)$ & $<0.001$ \\
\hline \multirow{2}{*}{$\begin{array}{l}\text { Lowest quartile of combined parent } \\
\text { gross income from all sources } \\
\text { when their child was aged } 15: \mathrm{n} \\
(\mathrm{Col} \%)\end{array}$} & Yes & $42(13.3)$ & $240(28.7)$ & $282(24.5)$ & \\
\hline & No & 273 (86.7) & $595(71.3)$ & $868(75.5)$ & $<0.001$ \\
\hline \multirow{2}{*}{$\begin{array}{l}\text { At least on parent unemployed/not } \\
\text { in the labour force when their child } \\
\text { was aged 15: } \mathrm{n}(\mathrm{Col} \%)\end{array}$} & Yes & $72(23.1)$ & $267(32.2)$ & 339 (29.7) & \\
\hline & No & 239 (76.9) & $562(67.8)$ & $801(70.3)$ & $<0.01$ \\
\hline \multirow{2}{*}{$\begin{array}{l}\text { Parent financial difficulties when } \\
\text { their child was aged 15: n (Col \%) }\end{array}$} & Yes & 65 (21.0) & $332(40.1)$ & $397(35.5)$ & \\
\hline & No & $244(79.0)$ & $476(58.9)$ & $720(64.5)$ & $<0.001$ \\
\hline $\begin{array}{l}\text { Mean parent occupational status }{ }^{c} \\
\text { when their child was aged } 15: M \\
\text { (SD) }\end{array}$ & & $5.08(3.15)$ & $7.45(3.21)$ & $6.80(3.36)$ & $<0.001$ \\
\hline
\end{tabular}

NS. Statistically non-significant. 
a Young person and parent mental health constructs scaled to range from 0-10. Higher scores indicate better mental health. ${ }^{\mathrm{b}}$ Physical functioning scale ranges from 0-10. Higher scores indicate better physical health.

${ }^{c}$ Parent occupational status reverse coded and rescaled to range from $0-10$. Higher scores indicate lower parent occupational status. 
Table 2. Unstandardized regression coefficients from latent state models of young person mental health: ages 15 to 21 ( $n=1734)$.

\begin{tabular}{|c|c|c|c|c|c|c|c|c|c|c|c|}
\hline \multirow[b]{2}{*}{ Predictors } & \multirow[b]{2}{*}{ Age } & \multicolumn{2}{|c|}{ Model 1} & \multicolumn{2}{|c|}{ Model 2} & \multicolumn{2}{|c|}{ Model 3} & \multicolumn{2}{|c|}{ Model $4{ }^{\mathrm{e}}$} & \multicolumn{2}{|c|}{ Model $5^{\mathrm{e}}$} \\
\hline & & $\mathrm{b}(95 \% \mathrm{CI})$ & $d$ & $\mathrm{~b}(95 \% \mathrm{CI})$ & $d$ & $\mathrm{~b}(95 \% \mathrm{CI})$ & $d^{d}$ & $\mathrm{~b}(95 \% \mathrm{CI})$ & $d^{d}$ & $\mathrm{~b}(95 \% \mathrm{CI})$ & $d^{d}$ \\
\hline \multirow{7}{*}{$\begin{array}{l}\text { University } \\
\text { students vs. } \\
\text { community } \\
\text { peers }\end{array}$} & 15 & $\begin{array}{l}0.41 * * * \\
(0.20,0.62)\end{array}$ & 0.22 & $\begin{array}{l}0.49 * * * \\
(0.27,0.70)\end{array}$ & 0.26 & $\begin{array}{l}0.45 * * * \\
(0.24,0.67)\end{array}$ & 0.25 & $\begin{array}{l}0.43 * * * \\
(0.21,0.65)\end{array}$ & 0.23 & $\begin{array}{l}0.35^{* *} \\
(0.13,0.58)\end{array}$ & 0.20 \\
\hline & 16 & $\begin{array}{l}0.30 * * \\
(0.08,0.52)\end{array}$ & 0.16 & $\begin{array}{l}0.40 * * * \\
(0.18,0.62)\end{array}$ & 0.21 & $\begin{array}{l}0.34 * * \\
(0.12,0.56)\end{array}$ & 0.18 & $\begin{array}{l}0.31 * * \\
(0.08,0.54)\end{array}$ & 0.17 & $\begin{array}{l}0.22 \\
(-0.01,0.44)\end{array}$ & 0.12 \\
\hline & 17 & $\begin{array}{l}-0.01 \\
(-0.23,0.21)\end{array}$ & 0.00 & $\begin{array}{l}0.09 \\
(-0.13,0.30)\end{array}$ & 0.05 & $\begin{array}{l}-0.01 \\
(-0.23,0.21)\end{array}$ & 0.00 & $\begin{array}{l}0.01 \\
(-0.21,0.23)\end{array}$ & 0.01 & $\begin{array}{l}-0.13 \\
(-0.35,0.10)\end{array}$ & -0.07 \\
\hline & 18 & $\begin{array}{l}0.40 * * * \\
(0.19,0.62)\end{array}$ & 0.21 & $\begin{array}{l}0.48 * * * \\
(0.27,0.70)\end{array}$ & 0.26 & $\begin{array}{l}0.41 * * * \\
(0.20,0.62)\end{array}$ & 0.23 & $\begin{array}{l}0.39 * * \\
(0.17,0.61)\end{array}$ & 0.21 & $\begin{array}{l}0.28^{*} \\
(0.06,0.50)\end{array}$ & 0.15 \\
\hline & 19 & $\begin{array}{l}0.36^{* *} \\
(0.13,0.59)\end{array}$ & 0.19 & $\begin{array}{l}0.43 * * * \\
(0.20,0.65)\end{array}$ & 0.23 & $\begin{array}{l}0.32 * * \\
(0.10,0.54)\end{array}$ & 0.18 & $\begin{array}{l}0.36^{* *} \\
(0.13,0.60)\end{array}$ & 0.20 & $\begin{array}{l}0.20 \\
(-0.04,0.43)\end{array}$ & 0.11 \\
\hline & 20 & $\begin{array}{l}0.01 \\
(-0.25,0.28)\end{array}$ & 0.01 & $\begin{array}{l}0.07 \\
(-0.20,0.33)\end{array}$ & 0.04 & $\begin{array}{l}-0.03 \\
(-0.29,0.24)\end{array}$ & -0.01 & $\begin{array}{l}-0.04 \\
(-0.32,0.23)\end{array}$ & -0.02 & $\begin{array}{l}-0.22 \\
(-0.50,0.06)\end{array}$ & -0.12 \\
\hline & 21 & $\begin{array}{l}0.33 * \\
(0.06,0.59)\end{array}$ & 0.17 & $\begin{array}{l}0.37 * * \\
(0.10,0.63)\end{array}$ & 0.20 & $\begin{array}{l}0.23 \\
(-0.03,0.50)\end{array}$ & 0.13 & $\begin{array}{l}0.30 * \\
(0.01,0.58)\end{array}$ & 0.16 & $\begin{array}{l}0.13 \\
(-0.15,0.41)\end{array}$ & 0.07 \\
\hline \multirow{7}{*}{$\begin{array}{l}\text { Gender: } \\
\text { Females vs. } \\
\text { males }\end{array}$} & 15 & --- & --- & $\begin{array}{l}-0.62 * * * \\
(-0.84,-0.41)\end{array}$ & -0.34 & $\begin{array}{l}-0.63 * * * \\
(-0.85,-0.42)\end{array}$ & -0.35 & $\begin{array}{l}-0.62 * * * \\
(-0.83,-0.40)\end{array}$ & -0.34 & $\begin{array}{l}-0.61 * * * \\
(-0.82,-0.39)\end{array}$ & -0.34 \\
\hline & 16 & --- & --- & $\begin{array}{l}-0.75 * * * \\
(-0.96,-0.53)\end{array}$ & -0.40 & $\begin{array}{l}-0.74 * * * \\
(-0.96,-0.53)\end{array}$ & -0.41 & $\begin{array}{l}-0.74 * * * \\
(-0.95,-0.52)\end{array}$ & -0.40 & $\begin{array}{l}-0.72 * * * \\
(-0.93,-0.50)\end{array}$ & -0.40 \\
\hline & 17 & --- & --- & $\begin{array}{l}-0.81 * * * \\
(-1.02,-0.60)\end{array}$ & -0.44 & $\begin{array}{l}-0.80 * * * \\
(-1.01,-0.60)\end{array}$ & -0.44 & $\begin{array}{l}-0.80 * * * \\
(-1.01,-0.60)\end{array}$ & -0.44 & $\begin{array}{l}-0.77 * * * \\
(-0.97,-0.57)\end{array}$ & -0.43 \\
\hline & 18 & --- & --- & $\begin{array}{l}-0.73 * * * \\
(-0.93,-0.52)\end{array}$ & -0.39 & $\begin{array}{l}-0.74 * * * \\
(-0.94,-0.54)\end{array}$ & -0.41 & $\begin{array}{l}-0.72 * * * \\
(-0.92,-0.52)\end{array}$ & -0.39 & $\begin{array}{l}-0.70 * * * \\
(-0.90,-0.50)\end{array}$ & -0.39 \\
\hline & 19 & --- & --- & $\begin{array}{l}-0.55 * * * \\
(-0.78,-0.33)\end{array}$ & -0.30 & $\begin{array}{l}-0.58 * * * \\
(-0.80,-0.35)\end{array}$ & -0.32 & $\begin{array}{l}-0.55 * * * \\
(-0.77,-0.32)\end{array}$ & -0.30 & $\begin{array}{l}-0.48 * * * \\
(-0.70,-0.26)\end{array}$ & -0.27 \\
\hline & 20 & --- & --- & $\begin{array}{l}-0.49 * * * \\
(-0.74,-0.24)\end{array}$ & -0.27 & $\begin{array}{l}-0.50 * * * \\
(-0.74,-0.25)\end{array}$ & -0.27 & $\begin{array}{l}-0.48 * * * \\
(-0.73,-0.23)\end{array}$ & -0.26 & $\begin{array}{l}-0.41 * * \\
(-0.65,-0.16)\end{array}$ & -0.23 \\
\hline & 21 & --- & --- & $\begin{array}{l}-0.35^{*} \\
(-0.62,-0.08)\end{array}$ & -0.19 & $\begin{array}{l}-0.37 * * \\
(-0.63,-0.10)\end{array}$ & -0.20 & $\begin{array}{l}-0.34 * \\
(-0.61,-0.07)\end{array}$ & -0.19 & $\begin{array}{l}-0.29 * \\
(-0.57,-0.02)\end{array}$ & -0.17 \\
\hline \multirow[t]{4}{*}{$\begin{array}{l}\text { Parent mental } \\
\text { health }\end{array}$} & 15 & --- & --- & --- & --- & $\begin{array}{l}0.13 * * * \\
(0.06,0.21)\end{array}$ & 0.24 & --- & --- & $\begin{array}{l}0.10^{*} \\
(0.01,0.19)\end{array}$ & 0.18 \\
\hline & 16 & --- & --- & --- & --- & $\begin{array}{l}0.13 * * * \\
(0.06,0.20)\end{array}$ & 0.24 & --- & --- & $\begin{array}{l}0.08 \\
(-0.02,0.18)\end{array}$ & 0.15 \\
\hline & 17 & --- & --- & --- & --- & $\begin{array}{l}0.19 * * * \\
(0.12,0.27)\end{array}$ & 0.35 & --- & --- & $\begin{array}{l}0.13^{*} \\
(0.03,0.23)\end{array}$ & 0.24 \\
\hline & 18 & --- & -- & --- & --- & $\begin{array}{l}0.15 * * * \\
(0.07,0.22)\end{array}$ & 0.26 & --- & -- & $\begin{array}{l}0.07 \\
(-0.03,0.16)\end{array}$ & 0.12 \\
\hline
\end{tabular}




\begin{tabular}{|c|c|c|c|c|c|c|c|c|c|c|c|}
\hline & 19 & --- & --- & --- & --- & $\begin{array}{l}0.24 * * * \\
(0.17,0.32)\end{array}$ & 0.44 & --- & --- & $\begin{array}{l}0.22 * * * \\
(0.13,0.31)\end{array}$ & 0.41 \\
\hline & 20 & --- & --- & --- & --- & $\begin{array}{l}0.22 * * * \\
(0.14,0.31)\end{array}$ & 0.41 & --- & --- & $\begin{array}{l}0.14^{*} \\
(0.02,0.25)\end{array}$ & 0.25 \\
\hline & 21 & --- & --- & --- & --- & $\begin{array}{l}0.21 * * * \\
(0.11,0.31)\end{array}$ & 0.38 & --- & --- & $\begin{array}{l}0.18 * * \\
(0.06,0.29)\end{array}$ & 0.33 \\
\hline \multirow{7}{*}{$\begin{array}{l}\text { Parent socio- } \\
\text { economic } \\
\text { position when } \\
\text { child aged } 15\end{array}$} & 15 & --- & --- & --- & --- & --- & --- & $\begin{array}{l}-0.12^{*} \\
(-0.22,-0.01)\end{array}$ & -0.19 & $\begin{array}{l}-0.24 * \\
(-0.46,-0.02)\end{array}$ & -0.27 \\
\hline & 16 & --- & --- & --- & --- & --- & --- & $\begin{array}{l}-0.17^{*} \\
(-0.29,-0.04)\end{array}$ & -0.28 & $\begin{array}{l}-0.31^{*} \\
(-0.61,-0.01)\end{array}$ & -0.34 \\
\hline & 17 & --- & --- & --- & --- & --- & --- & $\begin{array}{l}-0.15^{*} \\
(-0.28,-0.01)\end{array}$ & -0.25 & $\begin{array}{l}-0.38^{*} \\
(-0.71,-0.06)\end{array}$ & -0.42 \\
\hline & 18 & --- & --- & --- & --- & --- & --- & $\begin{array}{l}-0.19 * * \\
(-0.32,-0.06)\end{array}$ & -0.31 & $\begin{array}{l}-0.45 * * \\
(-0.76,-0.15)\end{array}$ & -0.50 \\
\hline & 19 & --- & --- & --- & --- & --- & --- & $\begin{array}{l}-0.12 \\
(-0.26,0.02)\end{array}$ & -0.20 & $\begin{array}{l}-0.16 \\
(-0.42,0.09)\end{array}$ & -0.18 \\
\hline & 20 & --- & --- & --- & --- & --- & --- & $\begin{array}{l}-0.21^{*} \\
(-0.38,-0.05)\end{array}$ & -0.36 & $\begin{array}{l}-0.39 * \\
(-0.74,-0.04)\end{array}$ & -0.43 \\
\hline & 21 & --- & --- & --- & --- & --- & --- & $\begin{array}{l}-0.14 \\
(-0.30,0.03)\end{array}$ & -0.23 & $\begin{array}{l}-0.24 \\
(-0.56,0.07)\end{array}$ & -0.27 \\
\hline \multirow{7}{*}{$\begin{array}{l}\text { Young person } \\
\text { mental health } \\
\text { intercepts a }\end{array}$} & 15 & $\begin{array}{l}7.54 \\
(7.40,7.67)\end{array}$ & --- & $\begin{array}{l}7.80 \\
(7.65,7.96)\end{array}$ & --- & $\begin{array}{l}7.83 \\
(7.67,7.98)\end{array}$ & --- & $\begin{array}{l}7.82 \\
(7.66,7.97)\end{array}$ & --- & $\begin{array}{l}7.86 \\
(7.70,8.03)\end{array}$ & --- \\
\hline & 16 & $\begin{array}{l}7.38 \\
(7.25,7.52)\end{array}$ & --- & $\begin{array}{l}7.71 \\
(7.55,7.87)\end{array}$ & --- & $\begin{array}{l}7.73 \\
(7.58,7.89)\end{array}$ & --- & $\begin{array}{l}7.73 \\
(7.57,7.89)\end{array}$ & --- & $\begin{array}{l}7.74 \\
(7.56,7.92)\end{array}$ & -- \\
\hline & 17 & $\begin{array}{l}7.36 \\
(7.23,7.48)\end{array}$ & --- & $\begin{array}{l}7.71 \\
(7.56,7.86)\end{array}$ & --- & $\begin{array}{l}7.74 \\
(7.60,7.89)\end{array}$ & --- & $\begin{array}{l}7.73 \\
(7.58,7.87)\end{array}$ & --- & $\begin{array}{l}7.67 \\
(7.30,8.03)\end{array}$ & --- \\
\hline & 18 & $\begin{array}{l}7.29 \\
(7.16,7.42)\end{array}$ & --- & $\begin{array}{l}7.61 \\
(7.46,7.77)\end{array}$ & --- & $\begin{array}{l}7.65 \\
(7.50,7.80)\end{array}$ & --- & $\begin{array}{l}7.63 \\
(7.48,7.79)\end{array}$ & --- & $\begin{array}{l}7.60 \\
(7.32,7.89)\end{array}$ & --- \\
\hline & 19 & $\begin{array}{l}7.38 \\
(7.23,7.53)\end{array}$ & --- & $\begin{array}{l}7.62 \\
(7.44,7.81)\end{array}$ & --- & $\begin{array}{l}7.69 \\
(7.51,7.87)\end{array}$ & --- & $\begin{array}{l}7.64 \\
(7.45,7.82)\end{array}$ & --- & $\begin{array}{l}7.24 \\
(6.89,7.59)\end{array}$ & --- \\
\hline & 20 & $\begin{array}{l}7.34 \\
(7.14,7.54)\end{array}$ & --- & $\begin{array}{l}7.56 \\
(7.33,7.79)\end{array}$ & --- & $\begin{array}{l}7.62 \\
(7.39,7.85)\end{array}$ & --- & $\begin{array}{l}7.59 \\
(7.35,7.82)\end{array}$ & --- & $\begin{array}{l}7.29 \\
(6.94,7.64)\end{array}$ & --- \\
\hline & 21 & $\begin{array}{l}7.33 \\
(7.06,7.59)\end{array}$ & --- & $\begin{array}{l}7.48 \\
(7.18,7.78)\end{array}$ & --- & $\begin{array}{l}7.56 \\
(7.26,7.85)\end{array}$ & --- & $\begin{array}{l}7.50 \\
(7.20,7.79)\end{array}$ & --- & $\begin{array}{l}7.46 \\
(7.04,7.89)\end{array}$ & --- \\
\hline $\begin{array}{l}\text { Young person } \\
\text { mental health } \\
\text { SD }^{\mathrm{b}}\end{array}$ & & $\begin{array}{l}1.88 * * * \\
(1.81,1.95)\end{array}$ & --- & $\begin{array}{l}1.85 * * * \\
(1.79,1.92)\end{array}$ & --- & $\begin{array}{l}1.82 * * * \\
(1.75,1.88)\end{array}$ & --- & $\begin{array}{l}1.84 * * * \\
(1.77,1.90)\end{array}$ & --- & $\begin{array}{l}1.78 * * * \\
(1.71,1.84)\end{array}$ & -- \\
\hline $\begin{array}{l}\text { Parent mental } \\
\text { health } \mathrm{SD}^{\mathrm{b}, \mathrm{c}}\end{array}$ & & --- & --- & --- & --- & $\begin{array}{l}1.66 * * * \\
(1.58,1.73)\end{array}$ & --- & --- & --- & $\begin{array}{l}1.66 * * * \\
(1.59,1.74)\end{array}$ & --- \\
\hline
\end{tabular}


Parent socio-

economic

position when

child aged 15

$\mathrm{SD}^{\mathrm{c}}$

Model fit

statistics

$\chi^{2}(d f)$

RMSEA

(90\% CI)

(891)

0.027

CFI/TLI

(0.026, 0.029)

$0.932 / 0.925$

$-$

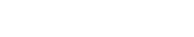

$* p<0.05 ; * * p<0.01 ; * * * p<0.001$

a Mean scores. Young person mental health constructs range from $0-10$, with higher scores indicating better mental health. All intercepts significant at $p<0.001$.

$\mathrm{b}$ Young person and parent mental health construct variances constrained to equality across young person ages.

c Parent mental health and socio-economic position when their child was aged 15 constructs mean centred.

d Parent mental health and socio-economic position when their child was aged 15 effect sizes $(d)$ are for \pm 1 SD.

${ }^{\mathrm{e}}$ Due to the use of numerical integration, overall fit statistics are not available for Models 4 and 5.

Note: Model 5 also adjusted for physical functioning, living with parents, and young person employment status (see Online Supplement, Table 6, for full results). All models were adjusted for response period 


\section{Figures}

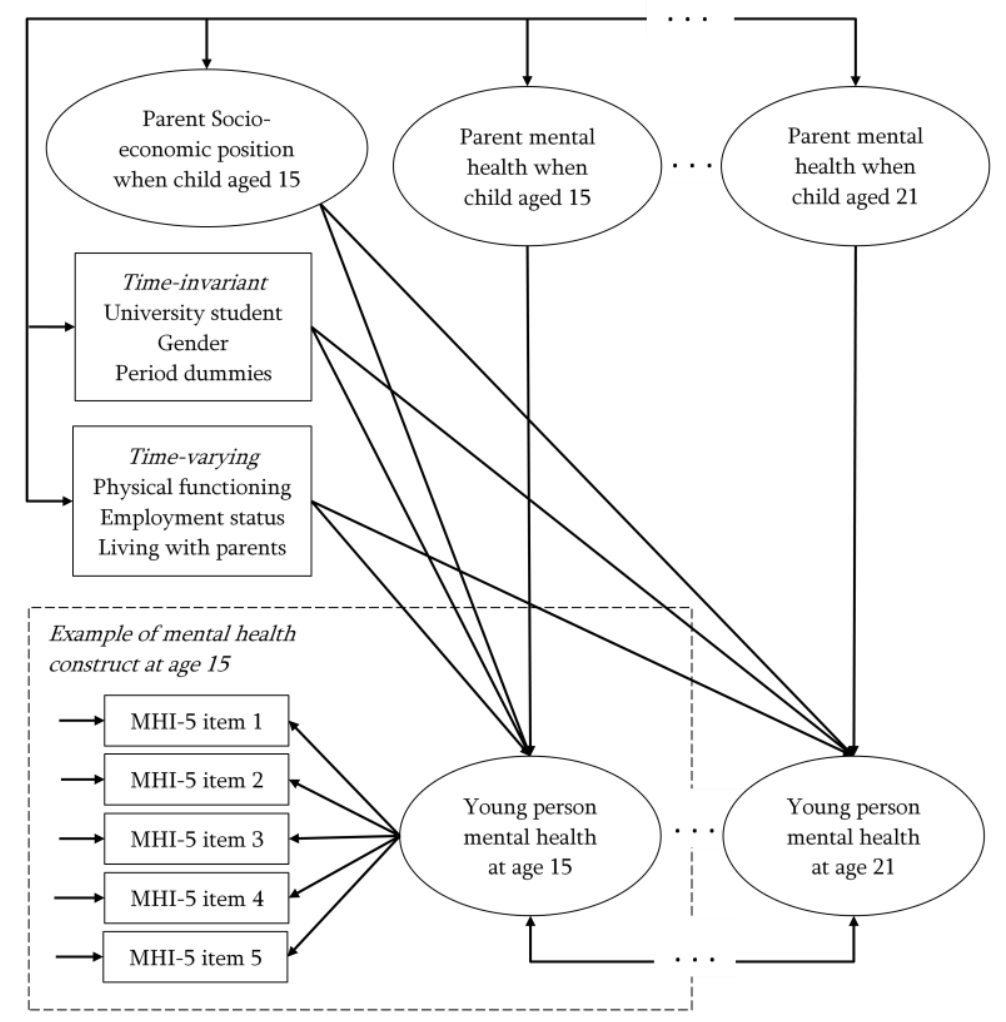

Note: Ovals represent latent constructs and rectangles represent observed variables. Young person and parent mental health constructs from ages 16 to 20 , and their relationship with the predictors, are not shown to save space.

Figure 1. Simplified path diagram of the full latent state model examining the mental health trajectories of university students relative to their community peers from ages 5 to 21 .

A

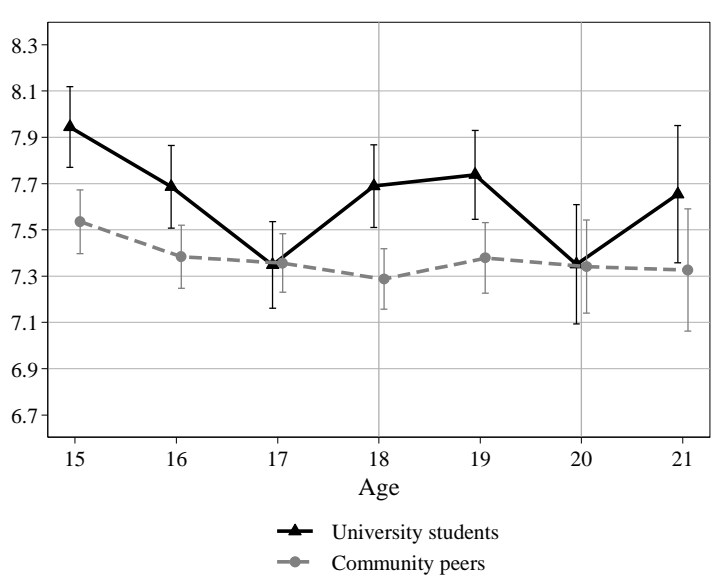

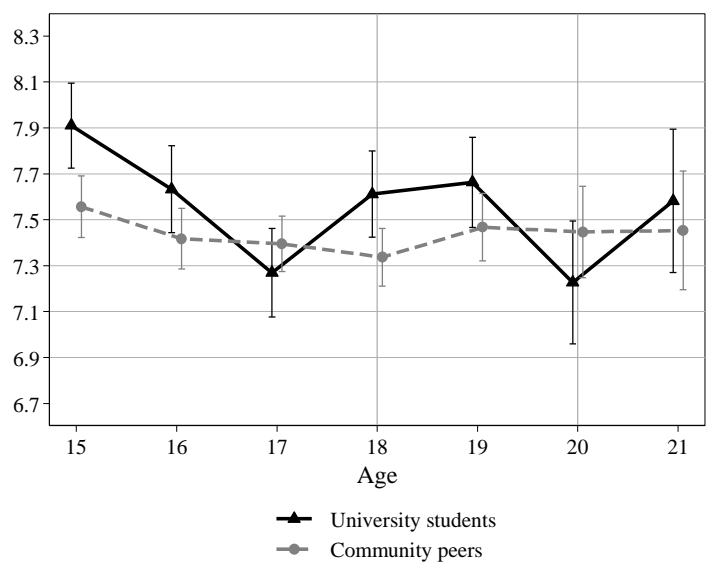

Figure 2. Young person mental health trajectories from ages 15 to 21: (A) University students vs. community peers (raw scores); (B) University students vs. community peers (adjusted for all covariates). 